\title{
Dokuz Eylül Üniversitesi Uygulama ve Araştırma Hastanesi Örneğinde Yönlendirme ve İşaretleme Tasarımında Stratejik Planlama
}

\author{
Tuğcan GÜLER *
}

\section{Özet}

Bu makale, tasarımcı kimliğiyle çevresel grafik tasarım ürünleri üzerine çalışan yazar tarafından yönlendirme ve işaretleme tasarımında yürütülmesi gereken süreçlerle ilgili bulgular ve önerileri, meslek profesyonelleri ve konuya ilgi duyan akademisyenlerle paylaşmak amacıyla hazırlanmıştır. Yönlendirme panolarının konumları ve bilgi mesajlarının oluşturulmasına yönelik alınması gereken kararların gerçekleştirilme yöntemleri, tespitler, keşifler, bulgular ve öneriler, hali hazırda bu makalenin yazarının proje başkanlığını yürüttüğg̈, Dokuz Eylül Üniversitesi Rektörlüg̈ü Bilimsel Araştırma Projeleri Koordinasyon Birimi tarafından desteklenen 2013.KB.SOS.007 kodlu 'Dokuz Eylül Üniversitesi Uygulama ve Araştırma Hastanesi Dış ve iç Mekan Sinyalizasyon Sistemleri Tasarımı ve Uygulaması' adlı bilimsel araştırma projesinden alıntılanan örnekler bağlamında anlatılmıştır. Projenin bel kemiğini oluşturan konumlandırma ve mesaj oluşturma süreçleri bu makalede kapsamlı bir şekilde incelenmiştir. Makale, yönlendirme stratejisi, kavşak noktalarının tespiti ve pano mesajlarının oluşturulması ile sınırlandırılmıştır. Makalenin odaklandığı sorunsal, yönlendirme ve işaretleme panolarının rasyonel yöntemlerle konumlandırılması ve gerekli bilgiler ile donatılacağı şeklinde tanımlanabilir.

Bu alanda Türkiyédeki tasarım projelerinin gerek tasarım problemi gerek uygulama derinliği adına yeterince kapsamlı olmadığı gözlemlenmektedir. Adı geçen Bilimsel Araştırma Projesinin amaçlarından biri bu alanda örnek bir uygulama yaparak ülkedeki tasarımcıların dikkatini bu yöne çekmektir.

Anahtar Sözcükler: Çevresel Grafik Tasarım, Yönlendirme ve İ̧aretleme Tasarımı, Stratejik Planlama, Bilgilendirme Tasarımı, Mimari Yönlendirme.

\section{Strategic Planning in Wayfinding and Signage Design on Example of Dokuz Eylul University Medical Applied Research Center (University Hospital)}

Abstract

This article is prepared to share findings and suggestions with professionals and interested academicians related to processes to be run in wayfinding and signage design by the author who works environmental graphic design products as a designer. The necessary decisions and application methods as well as determinations and explorations about the positioning and the message of signs quoted examples from 'Dokuz Eylul University Application and Research Hospital - Exterior and Interior Wayfinding and Signage Project' coded 2013.KB.SOS.007 that is officially supported by Dokuz Eylul University Coordination of Scientific Research Projects Division which is currently conducted by the author of this article will be discussed. Positioning and message creation processes, the backbone of the Project, have been examined extensively in this article. The content of this article is limited to wayfinding strategy, determination of junction points and sign messages. The problematic of the article can be define as how to be positioning signs in rational methods and equipping with necessary information.

It is observed that design projects in this field in Turkey are not comprehensive in both design problem and application diversity. One of the main aims of the dedicated scientific research project is to draw designer's attention in the country by having a proper examination.

Keywords: Environmental Graphic Design, Wayfinding and Signage Design, Strategic Planning, Information Design, Architectural Graphics. 


\section{Giriş}

Yedi milyara yaklaşan nüfusuyla dünya her geçen gün daha çok insana ev sahipliği yapmakta, ekonominin ve refahın gelişmesiyle insanlar daha çok hareket etmekte ve bu nedenle kentler kalabalıklaşmaktadır. Gelişen ve genişleyen dünyanın doğal sonucu ulaşım, sağlık, alışveriş ve eğlence gibi ihtiyaçların paylaşıldığı ortak kullanım alanlarının sayıları da hızla artmaktadır. Bu ve bunun gibi gelişmelerin sonucunda, kentlerin ve diğer tüm ortak mekanların tüm paydaşlar tarafından eşit seviyede kullanılabilmesi için, varlığı binlerce yıl öncesine giden yönlendirme ve işaretleme tasarımı, 20. yüzyılın ikinci yarısından itibaren bilinçli, sistematik ve bilimsel bir hassasiyetle, giderek yaygınlaşarak uygulanmaya başlanmıştır (Resim 1).

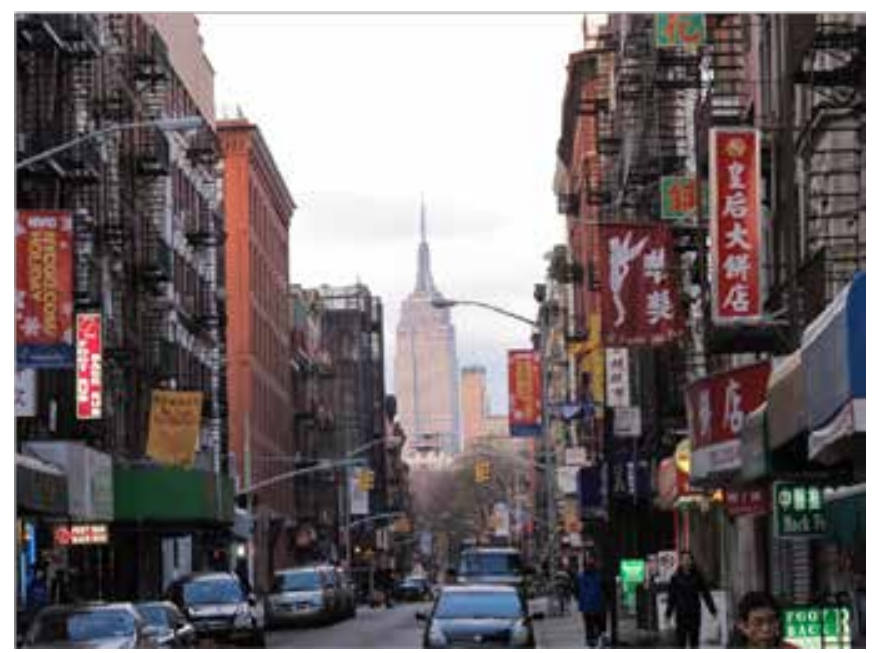

Resim 1. Artan nüfus ile kentler daha kalabalık bir hale gelmektedir. Çin Mahallesi, Manhattan, New York, 2012.

\section{Tarihsel Süreçte Yönlendirme ve İşaretleme Tasarımının Kullanımı}

Gelişim ve yaygınlaşması 20. yüzyılın ikinci yarısına referans verilmekle birlikte tarihsel süreçte yönlendirme ve işaretleme tasarımına ait örnekler Roma İmparatorluğu zamanına kadar gitmektedir. Çağın gelişmiş antik kentlerinde, nüfus ve yapılaşma yoğunluğunun getirdiği kentsel karmaşanın binaların üzerine ya da yanına yazdıkları isimler ile çözümlemeye çalışıldığı gözlemlenmektedir. Böylece hem mekanlar tanımlanmış hem de yapıların anıtsal kimliği desteklenmiştir.

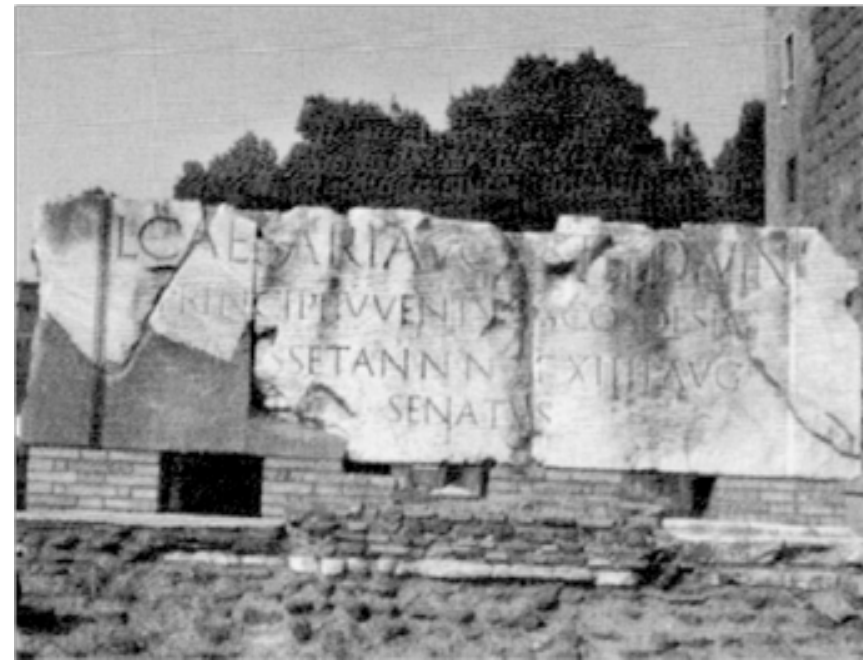

Resim 2. Antik dönemde bina üzerindeki isim ve uyarı yazıları yönlendirme işlevini de taşımaktaydı. Roma, İtalya, 2006.

\section{Yönlendirme ve İșaretleme Tasarımında Amaç}

Yönlendirme ve işaretleme tasarımının temel uğraşı kullanıcıyı bir mekanın en dış noktasından, iç mekanda varılmak istenen son noktaya (odaya/birime) yardım almaksızın ve kolaylıkla ulaştıracak tasarım sistemini kurmaktır. Kişinin yön bulmak için geçmiş deneyimleri ve alışkanlıklarından beslenemediği durumlarda tasarım elemanlarının aynı işlevi yüklenmesi amaçlanmaktadır (Arthur ve Passini, 1992: 32). Bu amaca hizmet eden projeler temel olarak yönlendirme panoları ve işaretleme panoları olmak üzere iki bileşenden oluşmaktadır. Yönlendirme panoları, hedeflenen adreslere ait bilgilerin -gerekirse her bir bilgi için ayrı ayrı- yön gösteren oklarla birlikte ifade edildiği panolardır. Işaretleme panoları ise varılan mekana ilişkin tanımlama yapan panoları içermektedir. Pano üzerinde yazan her bir bilgi 'mesaj' olarak adlandırılır. Mesaj ya da mesajlar stratejik plana göre belirlenir ve sıralanır. Yönlendirme panolarındaki mesajlar, yol üzerinde bulunan tüm birimlerin bilgileri şeklinde planlanır. Önemli olan bu 'süreçte' kullanıcılar nezdinde önem taşıyan mesajların, önem sırasına göre yerleşimidir.

Antik dönemin önemli kentlerindeki örneklerde de görülebildiği gibi giriş kapıları üzerinde taşa oyularak uygulanan yazılarda mekanın tanımı yapılmaktadır. Bununla birlikte henüz yönlendirme gereksinimin oluşmadığı çağda işaretleme çalışmalarının uyarı yazılarını da taşıdığı gözlem- 
lenmektedir (Calori, 2007: 2). İşaretleme tasarımının günümüz dünyasında yönlendirme panolarıyla birlikte çalışması gerektiği genel olarak kabul görmektedir (Muhlhausen, 2001: 2). Eski çağlarda bölgeyi bilen kullanıcıların çoğunlukta olduğu küçük alanlarda işlevini başarıly yerine getirebilmiştir. Yönlendirmenin iki ayağından biri olan mobilitenin o zamanlar düşük olduğunu söylemek yanlış olmayacaktır (Hogan, 2002: 4). Tıpkı günümüzde kendi mahallesinde yaşayan kişilerin yönlendirme tabelasına gereksinim duymadan yakındaki bakkala, otobüs durağına ya da komşusuna gidebilmesi gibi geçmiş zamanda yaşayan kişiler salt işaretlemelerle gereksinimlerini giderebilmişlerdir. İşaretleme tasarımının zamanında tek tasarım öğesi olarak işlev görebilmesi dünyanın göreceli olarak daha küçük, kentlerin birbirinden daha kopuk ve kullanıcıların daha az mobiliteye sahip olmasıyla açıklanabilir. Günümüzde her üç koşul da değişmiştir.

\section{Yönlendirme ve iş̧aretleme Tasarımında Uygulama Süreci}

Yönlendirme ve işaretleme tasarımı bir bütün halinde, girişten başlayarak varılmak istenen hedef noktaya kadar süreklilik, uyum ve görsel bütünlük içerisinde çalışan bir tasarım sistemidir. Projenin sistem olarak adlandırılması, tasarım öğelerinin birer dişli gibi birbiriyle uyumlu çalışma zorunluluğundan kaynaklanmaktadır. Mekan içerisinde işaretleme tabelasıyla tanımlanmış son kapıya ulaşıncaya kadar kullanıcılar yönlendirme panolarıly pek çok karar aşamasını geride bırakırlar. Bu nedenle anlaşılırlık ve algılanabilirlik büyük önem taşımaktadır. Proje parçalarının çevresiyle uyumlu ölçülerde olmasına ve kullanıcıların algı sahalarına giren noktalarda tercih edilmesine dikkat edilmelidir.

Projelerin bir ayağı yönlendirme bir ayağı da işaretleme tasarımı olmasına karşın, bu tür projeleri yeni uygulamaya başlayan mekanlarda işaretlemelerin sıklıkla ana gövde olarak uygulandığı görülmektedir. Tarihsel süreçte de benzerlikler görülmekte, işaretleme tasarımının daha eski tarihlere dayandığı gözlemlenmektedir. Günümüzde pek çok mekanda yönlendirme projesi adı altında isimlik panolarına yönlendirme oklarının eklenerek çalışıldığı görülmektedir. İşaretleme panosu mekan hangi amaçla kullanılıyorsa, kim kullanıyorsa tartışmaya ve şüpheye yer vermeyecek şekil- de net bilgi vermelidir. Bu nedenle tasarımcının proje mekanının tamamını en küçük detayına kadar tanıması büyük önem taşımaktadır (Resim 3).

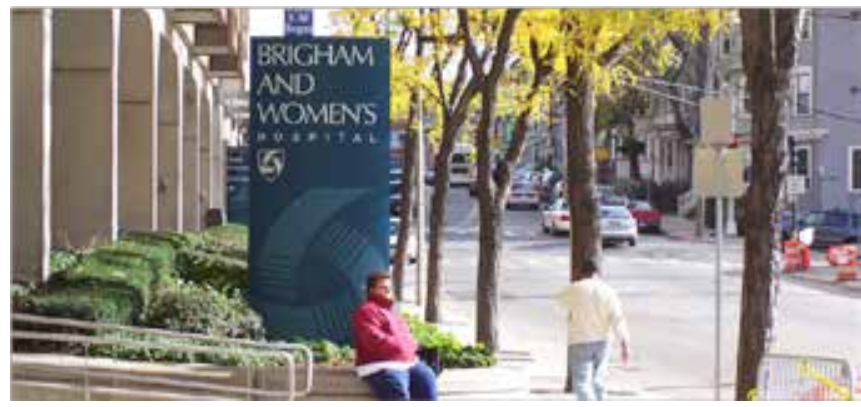

Resim 3. Brigham and Woman Hastanesi ana kapısı yola dar açıyla baktığı için isimlik panosu yola dik totem formunda hazırlanmıştır. Boston ABD, 2005.

Kalabalıklaşan kentlerde nüfustan daha hızlı artan mobilite nedeniyle, mekan tanımlama yöntemiyle çalısıılarn işaretleme tasarımı kullanıc gereksinimi açısından bugün yetersiz hale gelmektedir. Bu nedenle ilk örneklerine ortaçağ kentlerinde rastlanan yönlendirme tasarımı ortaya çıkmıştır (Resim 4).

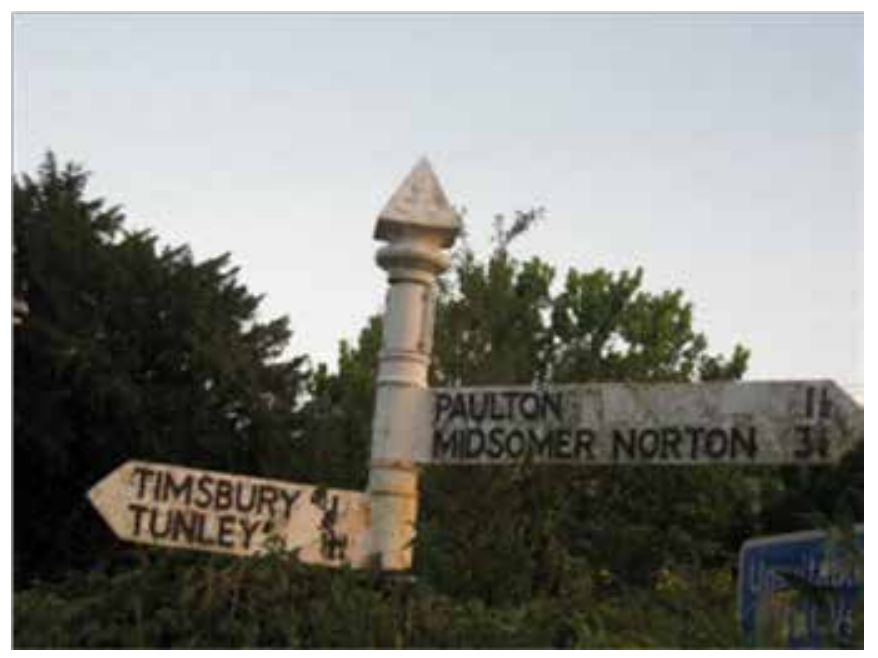

Resim 4. Temeli ortaçağ’a kadar uzanan yönlendirme çalışmaları, Bristol, İngiltere, 2007.

Yönlendirme tasarımının ilk ortaya çıkışını kentlerin kalabalıklaşmasına bağlamak mümkündür. Tek bir alan ya da ana bir yapı etrafında şekillenen antik dönem kentlerinin aksine ortaçağın büyük kentleri birden fazla cadde, meydan ve bunların arasındaki geçişlere sahipti. Mekanlar kimi yer- 
lerde birbiri ardına sıralanırken yapılar genel kent dokusu içerisinde aynılaşmakta ve ayırt edici nitelikler azalmaktadır. Üstelik genişlemeden ötürü bu mekanları 'bulmak' eskisi kadar kolay da olmamaktadır. Kentleşmenin getirdiği bir sorunun çözümü olan yönlendirme ve işaretleme tasarımı yol, bölge ve simge gibi bileşenlerden beslenerek gelişir (Lynch, 1960: 8).

Yönlendirme ve işaretleme tasarımında bir çalışmanın başarısı hiç bir biçimde pano formu, renkler ve tipografi gibi tasarım öğeleriyle açıklanmamalıdır; asıl çalışan unsur doğru konumlandırma/ doğru mesaj yoğunluğu olmalıdır. Sistem dahilinde üretilen tasarımların kullanıcılar tarafından kolay algılanabilmesi, kullanıcı davranışlarını olumlu yönde yönetebilmesi ve mekanın kullanıcılar tarafından rahatlıkla kullanılabilmesi, yönlendirme ve işaretleme tasarımında başarılı bir uygulamanın tanımıdır (Resim 5).

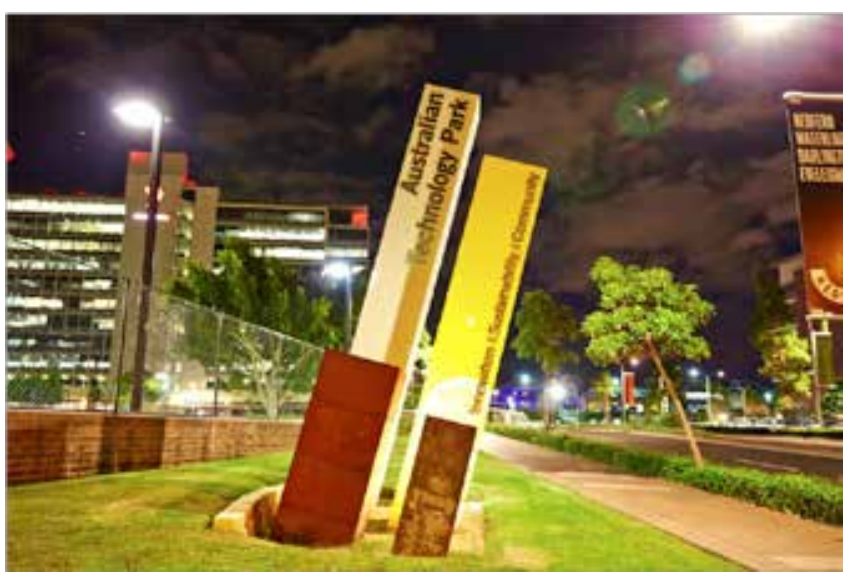

Resim 5. Yönlendirme ve işaretleme tasarımı ürünleri yalnızca estetik yönden değil, okunurluk ve anlaşıırlık yönünden de başarıı olmalıdır. Avustralya Teknoloji Parkı, Sydney, 2011.

Yönlendirme Tasarımında sisteminde tasarım süreci öncelikle mekanla ilgili verilerin toplanmasıyla başlar. Ardından toplanan verilerden yararlanılarak oluşturulan stratejik plan ile konumlandırma ve mesaj içeriklerine karar verilir. Stratejik planlamanın doğru kurgulanabilmesi için proje alanı derinlemesine analiz edilmelidir. Bu amaçla her türlü kaynaktan gelen verilerin toplanması, karşılaştırılması ve tasnif edilmesi gerekmektedir. Bu veriler mevcut planlar, uydu fotoğrafları, haritalar gibi belgelerin yanı sıra, alan üzerinde yapılacak keşiflerden elde edilen bilgilerden olu- şur. Mekanların gereksinimler doğrultusunda zamanla farklı kullanım biçimlerine dönüşeceği dikkate alınarak, keşif aşaması hassasiyetle yürütülmelidir.

Makaleye konu olan hastane ve çevre alanları üzerinde veri toplama aşamasına orijinal proje planlarıyla başlanmıştır. Zaman içerisinde yapılan değişikliklerin tespit etmek için tüm mekanlarda keşif yapılmaktadır. Özellikle kullanım amacı sabitlenmemiş, içeriği değişebilen mekanlara yönelik bilgilerin yapılacak keşifle edinilebileceği söylenebilir. Hastane alanı içerisinde tedavi birimlerinde çok sayıda değişiklik olmazken akademisyenlerin odaları ile hastaları doğrudan bağlamayan küçük mekanlarda yoğun değişlikler olduğu gözlemlenmektedir. Tüm bu verilere keşif çalışmalarıyla ulaşılabilir.

Mevcut planlardaki yerler ile güncel kullanım arasındaki farklar, plan ya da uydu haritası üzerinde algılanması zor olan kavşak ya da geçiş noktaları, bitki örtüsü ve ağaçlar gibi unsurlar veri toplama sürecinde detaylı bir biçimde kaydedilmelidir. Saha çalışması ve gerekli keşifler yapılmadan masa başında tasarlanan projelerin ciddi işlev sorunlarına sahip, noksan projeler olacağını söylemek yanlış olmayacaktır (Resim 6).

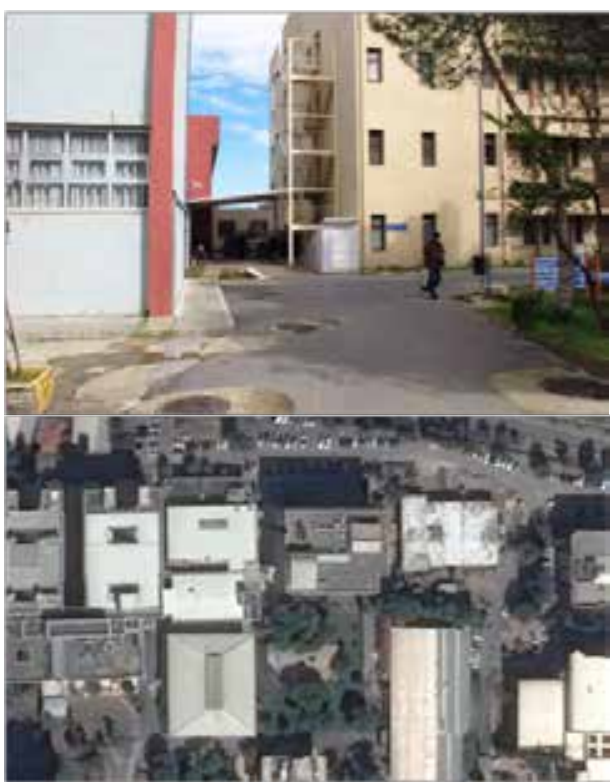

Resim 6. Uydu fotoğrafında ağaçlar tarafından örtülen kavşak noktası yapılan keşif sonucu fark edilmiştir. Dokuz Eylül Üniversitesi Hastanesi Bahçesi, 2013. 
Yönlendirme ve işaretleme tasarımı projeleri adeta terzi elinden çıkan özel dikim elbiseler gibi mekana özel tasarlanır. Yönlendirme ve işaretleme projeleri mekanın değişkenliklere ve kullanıcı gereksinimlerine uyum sağlayan özel tasarımlar olmalıdır. Bu nedenle projenin bağlanabileceḡi standartlardan bahsetmek olanaklı deḡildir. Standartlaştırma ve bu standartların tüm bileşenlerde sürdürülebilmesi projenin tamamlanması ve sürdürülebilirliği için önemli olmakla birlikte tek tipleştirme yaratmak yalnızca karayollarında kullanılan yönlendirme sistemleri için olanaklı görünmektedir.

Veri toplama aşamasında keşif süreci ve plan analizleri tamamlandıktan sonra mekana ait stratejik planlama sürecine başlanabilir. Pano mesajları da bu sürecin ardından oluşturulacaktır.

Türk Dil Kurumu sözlüğünde 'strateji' sözcüğü, "Bir ulusun veya uluslar topluluğunun, barış ve savaşta benimsenen politikalara destek vermek amacıyla politik, ekonomik, psikolojik ve askerî güçleri bir arada kullanma bilimi ve sanatı" (tdk, 2014) şeklinde ifade edilmektedir. Askeri kökenli bu sözcüğün projeyi tanımlarken kullanılması tesadüf deḡildir. Tanımın içinde yer alan 'çok disiplinlilik' ve 'yönetme sanatı' gibi kavramlar nedeniyle strateji sözcüğü kullanıcı gereksinimlerinin homojen bir yapıyla çözümlenmesi çabasını ifade etmeye uygun düşmektedir. Tasarımın doğru yerde doğru içerikle yer alarak varlığını kendi başına sürdürebilmesi stratejik kararların doğru verilmesiyle mümkün olacaktır. Stratejik planlama basit ya da standart bir planlama değildir. Bununla birlikte elektrik ya da su tesisatı gibi salt matematiksel bir planlama çalışması da değildir. Amaç, gerekli ve önemli mesajları gerekli ve önemli yerlerde sunmaktır. Bununla birlikte her kavşak noktasında her bilgiyi kullanıcılara vermek şeklinde de düşünülmemelidir. Algılanabilecek kadar yalın ve gözden kaçamayacak kadar sık olması gereken tasarımlar optimum parça ve mesaj sayısına sahip olmalıdır.

En temel yön bulma eylemlerinden biri olan 'göz ile taramak' kalabalıklaşan ve karmaşıklaşan kentlerde artık mümkün olamamaktadır. Gidilecek yer hemen arka sokak olsa dahi göz ufkunun önüne çıkan bir yapı 'göz ile tarayarak bulma' eylemini ortadan kaldırmaktadır (Resim 7).

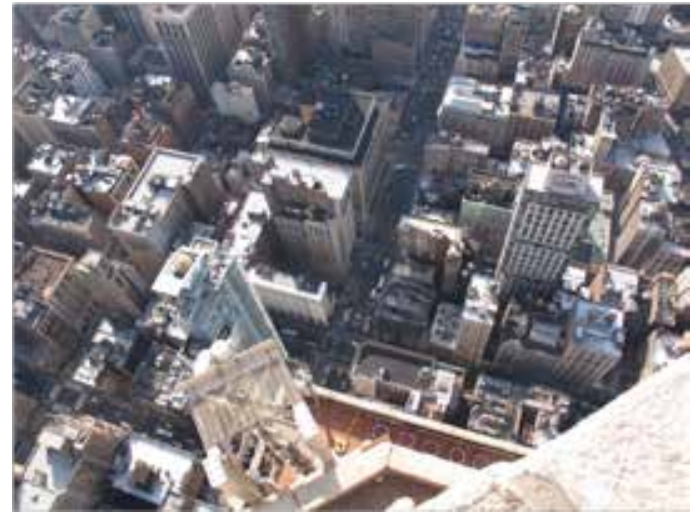

Resim 7. Binaların yarattığı perdeleme, kentlerde bir sonraki sokağın dahi gözle görülmesine engel olmaktadır. Manhattan, New York, ABD, 2012.

Caddeler ve sokaklarla biçimlenen kentlerde, binalar, duvarlar, bahçelerin varlığının geometrik olmayan kent planlamalarıyla birleşimi göz ufkunun 'menzilinin kısalması' sonucunu doğurmuştur. Burada aktarılan problemi salt kent örneğinde tartışmak doğru olmaz. Daha küçük yerleşim yerlerinde de insanlar belirli kentsel planlar ölçeğinde yaşarlar ve aynı ufuk darlığı sorunu orası için de geçerlidir. Ancak küçük yerleşim yerlerinde kullanıcılar (o bölgenin sakinleri) yaşadıkları ya da çalıştıkları yerlere daha aşina oldukları için bu yazıda dile getirilen yönlendirme problemlerini yaşamıyor olabilirler. Yönlendirme ve işaretleme tasarımındaki problemler daha çok büyük mekanlara özgüdür. Kent içerisinde, kent sakinleri aşina olmadıkları her bölgede kaos yaşayabilirler. Kaosun tek çözümü yönlendirme ve işaretleme tasarımının, işin profesyonelleri tarafından yerinde ve tam uygulanmasıdır (Resim 8).

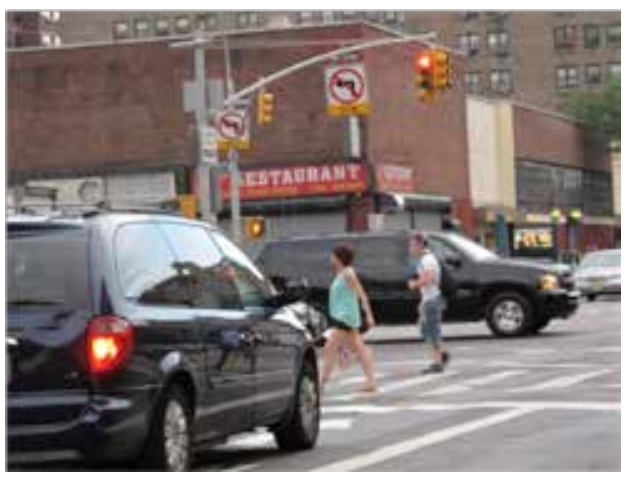

Resim 8. Yönlendirme tasarımı özellikle kent trafiḡinin yoğun olduğu yerlerde yaya ve araç güvenliğinin önemli bir yapı taşıdır. Queens, New York, ABD, 2012. 
Temelde düz giden bir yolun ikiye ya da daha çok yola ayrıldığı yer kavşak noktası olarak tanımlanmaktadır. İster kent sınırlarının dışında bir yer, ister kent içinde bir sokak isterse bir binanın koridorları olsun yolun ikiye ayrıldığı her noktada kullanıcı önündeki seçeneklerden (yollardan) birini tercih etmek, bir başka deyişle karar vermek zorundadır. Tasarımın amacı da bu karar anında kullanıcının gereksinimlerini öngörerek "kendisi için doğru kararı" vermesini sağlamaktır. Boş bırakılmış, sistemin dışında kalmış kavşak noktaları aşina olmayan kullanıcılar nezdinde güvensizlik ve gerilim yaratır.

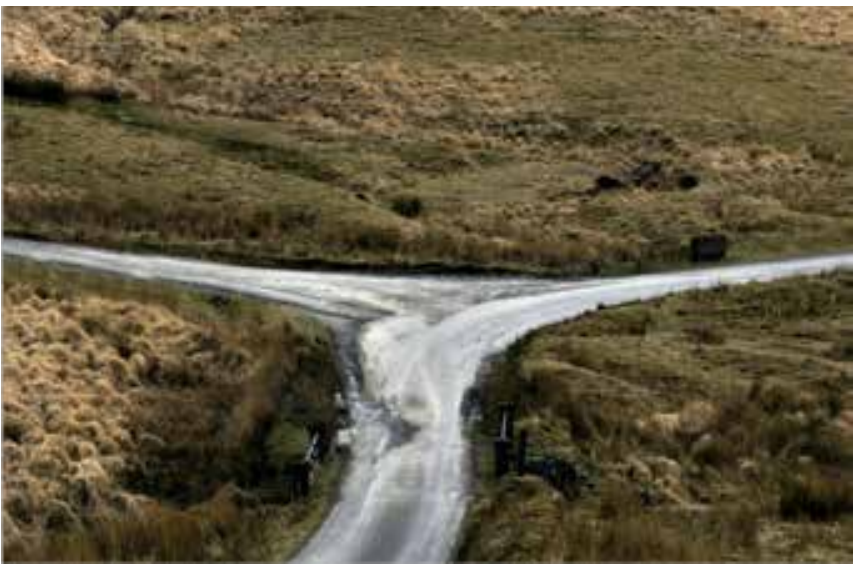

Resim 9. Tanıdık olmayan mekanlardaki belirsiz kavşaklar kişinin üzerinde gerilim yaratır. İngiltere, 2012. (Howard Kingsnorth/Corbis)

Bu yazıya konu olan Dokuz Eylül Üniversitesi Hastanesinin iç ve dış mekanlarında pek çok kavşak noktası bulunmaktadır. İç mekandaki kavşak noktaları çoğunlukla koridorlarda, az sayıda da blok birleşim yerlerindedir. Kullanıcı (bu örnekte hasta ya da hasta yakını) bu kavşak noktalarından birine geldiğinde gitmek istediği yer için doğru kararı verebilmelidir. Stratejik planlamanın özel bir planlama olduğundan hareketle, kullanıcının muhtemel varış noktalarının tümünün genel bilgi panosunda bulunmasının hastane gibi büyük mekanlarda mümkün olamayacağı, bu nedenle hiyerarşik yerleşim planının kullanıcılara kademeli bilgilendirmeyle erişim sunabileceği söylenebilir (Resim 10).

Yönlendirme ve işaretleme projeleri uygulanacağı mekanın salt fiziksel karakterine göre değil, kullanıcı hareketleri ve alışkanlıklarına göre de tasarlanır. Bu nedenle her proje benzersizdir. Bir kurum, iki farklı noktada tamamen aynı bi- rimlere sahip olsa dahi iki proje birbirinin kopyası olamaz. Mekanın bulunduğu coğrafi koşullar, kullanıcı profilindeki farklılıklar, iklim vb. gibi unsurlar her iki projeyi de farklı ve benzersiz kılacaktır.

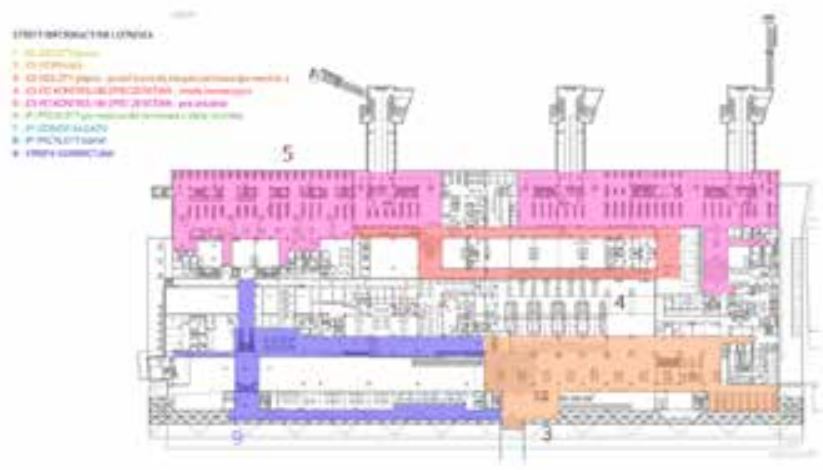

Resim 10. Krakow Havalimanı renk kodlarıyla yön bulma bölge bilgileri, Krakow, Polonya, 2013.

Stratejik planlama dış mekanla başlar ve iç mekandaki kapı işaretlemesine kadar sürer. Bu amaçla öncelikle kullanıcının dış mekandan iç mekana geçişi yönetilmelidir. Tasarımcıların bu hedefe giden yolda iç ve dış mekanları doğru tanımlamaları gerekmektedir. Yazı konusuna örnek olan Dokuz Eylül Üniversitesi Hastanesinde kullanıcıların aradıkları noktanın kapısına ulaşmaları birinci hedeftir. Hastane kampüs alanının üç tarafı yollarla çevrilmiş olup, bu yolların biri İzmir'in en uzun ana caddelerinden biri olan Mithatpaşa Caddesi'dir. Hastaneye gelen kullanıcıların çoğunluğu bu caddeden hastaneye giriş yaparlar. Kampüs alanının etrafı duvarlarla çevrilmiş olmasına karşın dış ve iç mekan girişleri engelsiz ve açıktır. Dış mekanda yapılan yönlendirme çalışmalarını, iç mekana göre zorlaştıran ve farklılaştıran en temel unsurlardan biri dış mekandaki yolların muğlaklığıdır. Kampüs alanı içerisinde yeterli sayıda belirlenmiş yol bulunmasına karşın -alçak çalılar dışında- yayaların yol dışı çapraz geçişlerini önleyecek bir engel bulunmamaktadır. İç mekanda hasta hareketleri koridor ve katlarla son derece net bir biçimde planlanabilirken dış mekandaki serbestlik, dikkat dağıtma potansiyeline sahip mimari yapılar ve kontrolsüz peyzaj kullanıcıların mekanı algılamasını zorlaştırmakta, tasarımcılara da daha çok sorumluluk yüklemektedir (Resim 11). 


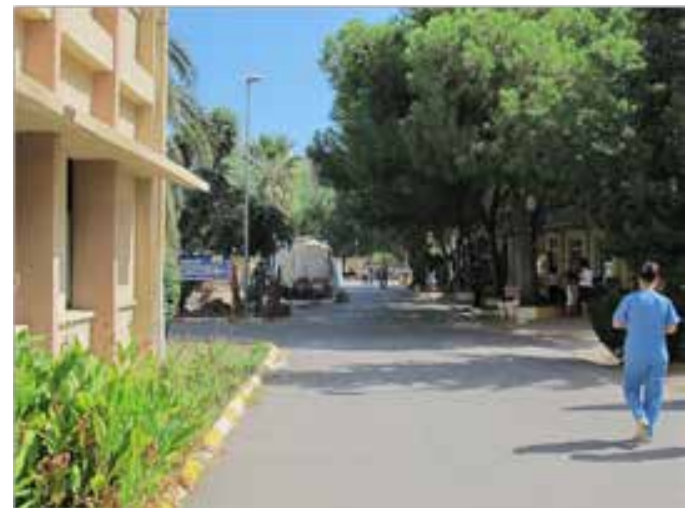

Resim 11. Dokuz Eylül Üniversitesi Hastanesi bahçe alanında ağaçlar ve diğer yeşilliklerden oluşan peyzaj, kullanıcıya ait alanlarda kontrolsüz gelişerek yönlendirme tasarımına engel olabilir hale gelmiştir.

Dokuz Eylül Üniversitesi Hastanesi, İzmir, 2013.

Bütün kavşak noktaları kullanıcının gideceği yöne ilişkin tercihte bulunacağı, karar vereceği noktalardır. Bu nedenle kullanıcının muhtemel güzergahı üzerindeki kavşak noktaları doğru belirlenmeli ve stratejik plan doğru mesajlarla oluşturulmalıdır. Yapılan toplantılarda yazıya konu olan hastane alanı içerisinde yalnızca bahçeden ulaşılabilen yaklaşık 60 farklı birim bulunduğu tespit edilmiştir. Kavşakların yerleri, panoların konumları ve panoların yönleri toplantılarda kararlaştııımıştır (Resim 12). Kavşak noktasının tespitinde öncelik kullanıcıların (hasta ve hasta yakınları) gereksinimleridir. Bununla birlikte hedef kullanıc grubuna dahil olmayan öğrenci ve personelin de yapılacak çalışmadan fayda sağlayacağı açıktır. Dış ve iç tüm mekanlar 'ilk kez gelen (first-timer)' kullanıcıya göre tasarlandığında diğer tüm paydaşları da başarıyla kucaklayacaktır.

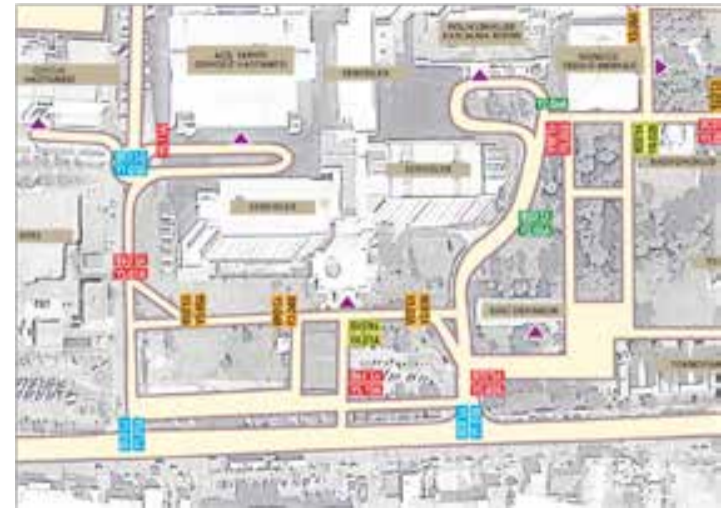

Resim 12. Hastane Dış Mekanda tespit edilen kavşak noktaları. Proje Dosyasından alınmıştır, 2013.
Dış mekanlar, yarı planlı bir alanda pek çok kontrol dışı unsurla başa çıkmak zorunda kalma dezavantajını tek hacimli olma avantajıyla dengelerken; iç mekanlar çok hacimli (katlar ve bloklar) olma dezavantajını planlı bir alanda oluşturulma avantajıla dengelemektedir. Bu nedenle iç mekanda yönlendirme stratejisinin temelini binanın mimari yapısının oluşturacaḡı söylenebilir. İç mekanda kullanıcı en temel yön duygusunu (ileri-geri) dahi karıştırabilir. Bu nedenle iç mekandaki yönlendirme panoları, kat/blok/bina bilgileriyle desteklenmeli; bunların yanı sıra gerekli yerlere mevcut konumu gösteren çalışmalar yerleştirilmelidir. İç mekanda kavşak noktaları birden fazla yöne bölünen koridorlar, merdivenler ve asansörler olacaktır (Resim 13).

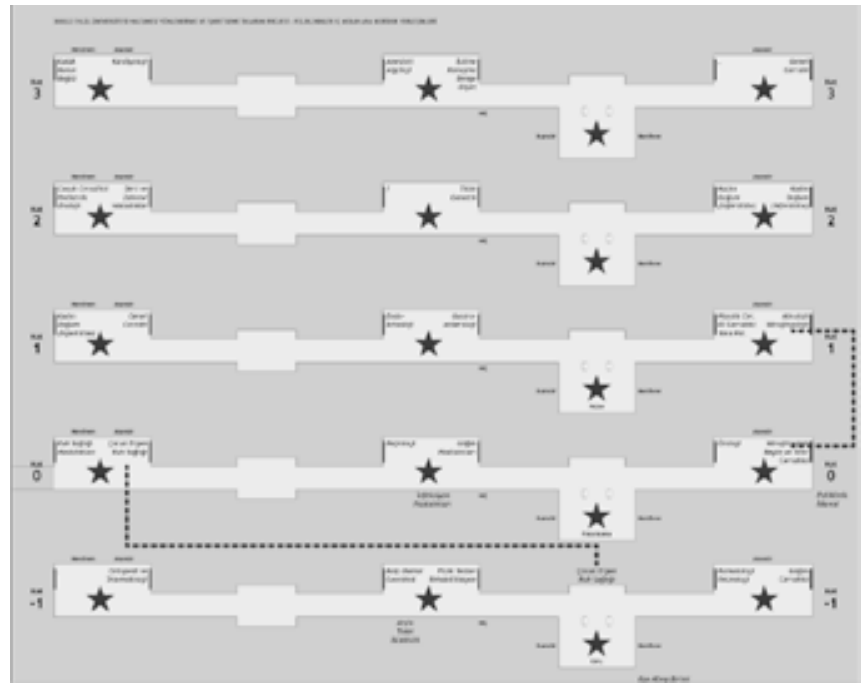

Resim 13. Hastane iç mekanda poliklinikler bloklarından yerleşim. En alttan itibaren bodrum kat dahil toplam 5 katlı bina. Her yıldız bir kavşak noktasını göstermektedir.

iç mekan ile dış mekan arasındaki en büyük yönetim farklıı̆ı̆ tasarımların boyutlandırılmasında yaşanmaktadır. Bu nedenle yönlendirme panolarında doğru konumlandırmaya ek olarak doğru frekansta (sıklıkta) konumlandırma zorunluluğu bulunmaktadır. Yazıya konu olan Dokuz Eylül Üniversitesi Hastanesinde frekans daha çok önem kazanmaktadır. Hastane içerisinde yalnızca poliklinikler ana koridor uzunluğu yaklaşık 90 metredir. Dolayısıyla servisler kapısından giren ve -örneğin- Genel Cerrahi polikliniḡine varmayı hedefleyen bir hastanın polikliniğe gidişi, polikli- 
niklerden sonra yönlendirileceği üçüncü bir birime geçişi (örneğin radyoloji) ve çıkışı yaklaşık 300 metrelik yürüyüş anlamına gelmektedir. Hasta olarak tanımlanmış bir kullanıCı için bu mesafe kesinlikle kısa değildir. Bu nedenle dikkat edilmesi gereken yol boyunca kullanıcıyla mekan arasındaki görsel iletişim bağının kopmamasını sağlamaktır. Bu bağı kurmanın ve sürdürmenin biricik yolu oluşturulacak yönlendirme ve işaretleme tasarımı ürünleriyle hastanın görüş alanında kesintisiz var olmaktır (Resim 14).

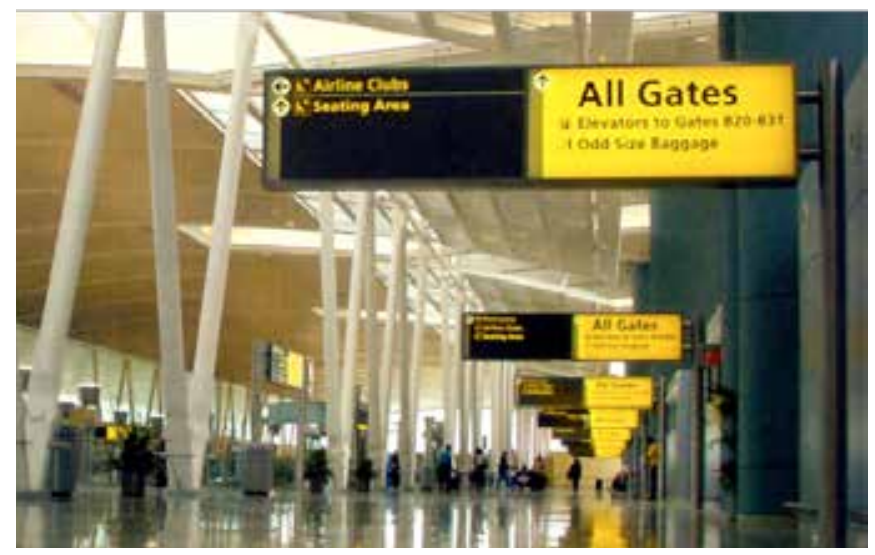

Resim 14. Yönlendirme ve İşaretleme Panoları kullanıcının görüş alanında kesintisiz yer almalıdır. JFK Havalimanı, New York, ABD, 2006.

Yönlendirme tasarımında stratejik planlama, kavşak noktaları belirlendikten sonra yönlendirme mesajlarının oluşturulmasıyla devam etmektedir. Hastane örneğinde kavşak noktaları belirlendikten sonra plan üzerinde giriş kapıları nezdinde kullanıcılara yönelik tüm birimler listelenerek kullanıcı gereksinimlerine göre gruplanmıştır. Dış mekanda yer alan birimler ile iç mekana geçen noktanın hemen yakınlarında yer alan birimlere listelemede öncelik verilmiştir. Birim sayısının fazlalığı nedeniyle kavşak noktalarındaki bilgi mesajları birimleri anlatan "ana başlıklar" ve "yakınlardaki yerler" şeklinde kurgulanmıştır.

Her bir yönlendirme panosu, bir önceki ve bir sonraki pano ile ilişkili olmalı, mesajların görsel sürekliliği sağlanarak kopukluk yaşanmamasına dikkat edilmelidir. Bu nedenle pano mesajları kullanıının ilk karşılaşacağı panodan başlanarak, internet sitelerindeki "site haritası"na benzer bir yapıda öncelikle ihtiyaçlar ve bölgedeki birimlerle hedefe yaklaştıkça da alt birimlerle gösterilmelidir (Resim 15).
Proje örneğindeki hastaneye çeşitli konularda benzerlik gösteren ABD'nin Boston kentindeki Massachusetts General Hospital'da eski ve yeni bloklar doğru stratejik planlamayla birbirine bağlanmıştır. Hastane binalarının çeşitli ve çok sayıda, kat sayıların da farklı ancak genelde yüksek olması sonucu yönlendirme stratejisi yatay hareketleri bina koridorları ile; dikey hareketleri ise koridorlar üzerinde bulunan asansör adaları ile çözümleme üzerine kurgulanmıştır (Resim 16).

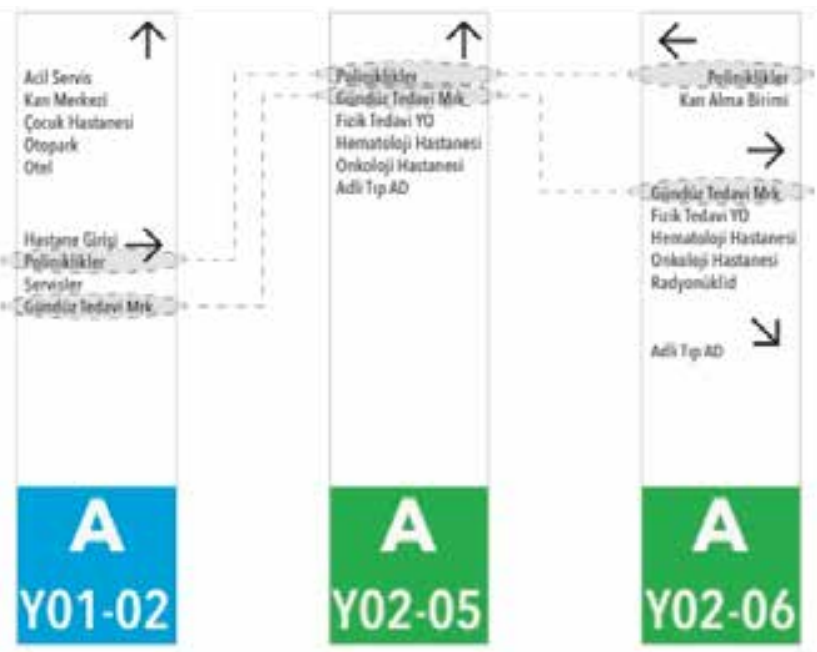

Resim 15. Yönlendirme totemlerinin mesajları (soldan sağa) önce ana bölüm (işaretli mesajlar), yaklaştıkça hiyerarşik olarak alt bölüm bilgileri gösterilmektedir.

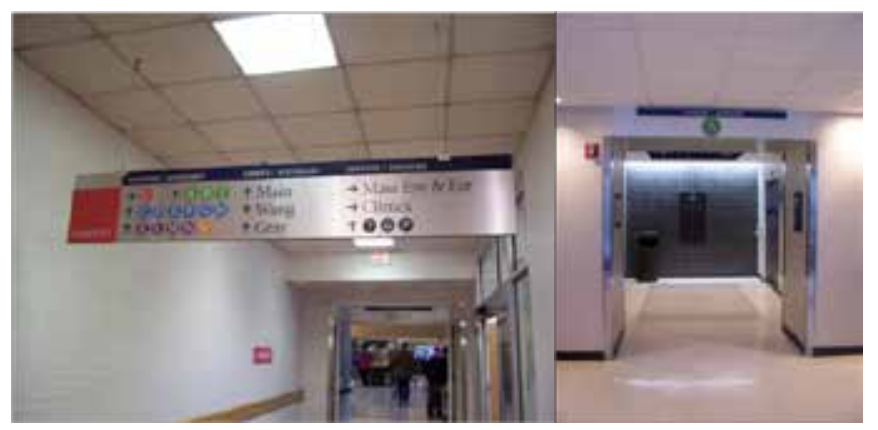

Resim 16. Mass General Hastanesindeki yüksek birim yoğunluğu yönetebilmek için koridorlar yatay, asansörler dikey aks olarak belirlenmiş, pano mesajlarında da yalnızca asansör adalarının kodlarına yer verilmiştir. 
Dokuz Eylül Hastanesi'ndeki projede ise ilk önce dış mekanda hastane bahçesi içinde kalan tüm birimlerin listesi çıkartılmışır. Öncelik sıralaması yapılırken dışarıdan acil erişime açık olması gereken acil servis ve kan alma birimi noktaları da ana yapıya dahil edilmiştir. Dış mekanda pano mesajı olarak dikkate alınması gereken yerin sayısının çokluğu sonucu öncelikler sıralaması yapılmış ve pano bilgilerinin akademik hiyerarşiye göre değil kullanıııların gereksinimlere göre düzenlenmesine karar verilmiştir. (Resim 17).

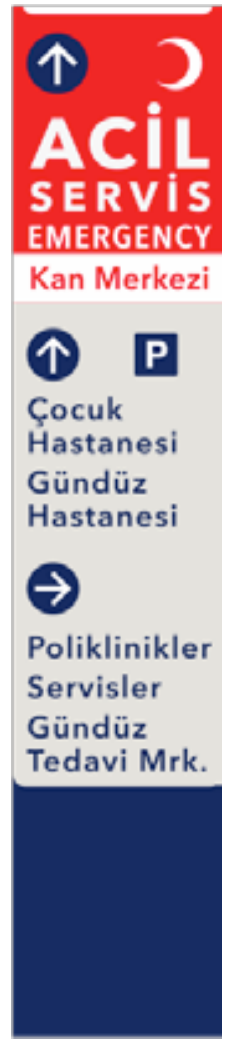

Resim 17. Hastane yüksek totem çalışması. Hastane kullanıcılarının gereksinimlerini karşılamak amacıyla acil durum mesajları ile gündelik mesajlar birbirlerinden tamamen ayrı konumlandırılmıştır.

Planlama süreci masa başında başlamış, sahada yapılan keşiflerle devam etmiş, masa başında yapılan stratejik planlama ve pano mesajlarının belirlenmesiyle tamamlanmıştır. Daha sonra pano konumları ve pano mesajlarındaki doğruluk hazırlanan maket üzerinde ve maketle birlikte saha çalışması yapılarak kontrol edilmiş, plan üzerinde masa başında öngörülemeyen detaylar da çözüme kavuşturulmuştur (Resim 18).

\section{Sonuç}

Yönlendirme ve işaretleme tasarımı projelerinde stratejik planlama tüm projenin omurgasını oluşturmaktadır. Kullanıcıların varmak istedikleri hedefe kesintisiz ve konforlu bir şekilde varabilmeleri doğru tasarım ürünlerinin doğru yerlere doğru içerikle konumlandırılmasıyla mümkündür. Yanlış konumlandırılan tasarım ürünleri, ne kadar estetik olurlarsa olsunlar gözden kaçacak ve görevini yerine getiremeyerek sistemde aksaklıklara neden olacaktır. Kullanıcıların dikkatini çekerek 'kendine baktıran' estetik tasarım ürünleri, kullanıcıyla karşılaştığı kısa sürede gerekli bilgileri aktararak görevini yerine getirmesi bütün yönlendirme ve işaretleme tasarımı projelerinin ortak amacı olmaya devam edecektir. Projenin parça sayısından tipografik tasarımına, mesajlarından frekansına kadar tüm final çıktıları stratejik planlamanın doğru yapılmasıyla amacına hizmet edecektir.

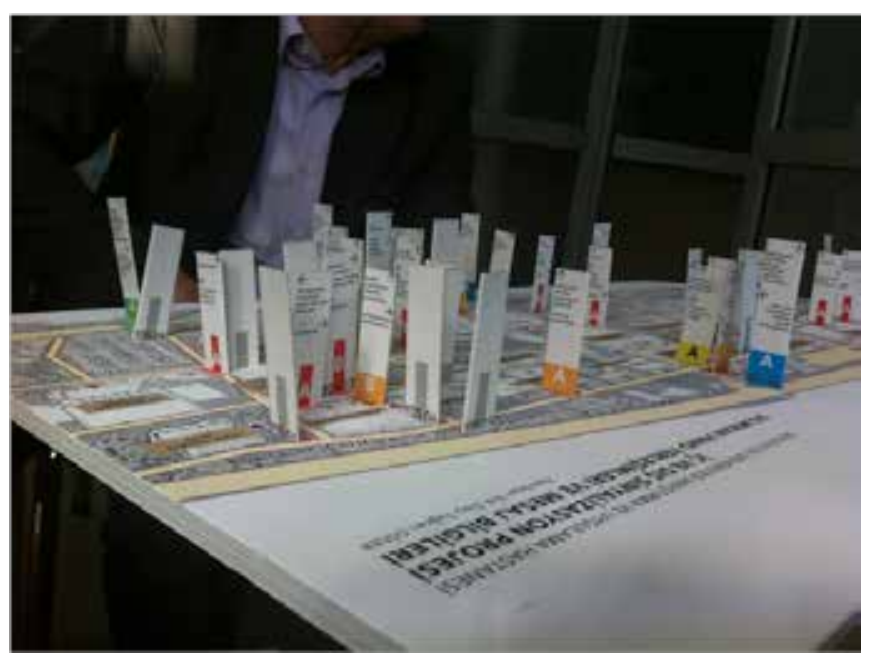

Resim 18. Uydu fotoğrafları ve resmi planlardan yararlanılarak oluşturulan dış mekan yerleşim maketi üzerinden pano mesajlarının birbirlerini karşılayışı ve süreklilik kontrol edilmiştir.

Yazıya konu olan Dokuz Eylül Üniversitesi Hastanesi'nde poliklinikler ve hasta ilişkileri konusunda yetkili müdür ve müdür yardımcısıyla yapılan toplantılarda kavşak noktaları planlar üzerinden ve sahada keşiflerle tespit edilmiştir. Plan üzerinde yapılan çalışmalardan sonra her bir kavşak noktası civar çalışanlarından alınan geri bildirimler ve hastanenin günlük yoğunluğuyla karşılaştırılarak kavşağın mesaj öncelikleri belirlenmiştir. Plan üzerinde geçişe elverişli görünen 
bir yerin, gerçekte mimari ve peyzaj sorunları nedeniyle geçişe elverişli olmadığı gözlemlenmiştir. Stratejik plan oluşturulurken plan ve güncel uydu fotoğrafları kullanılarak oluşturulan maket üzerinde yapılan çalışmalar ve bizzat maketin kampüs alanı içerisinde dolaştırılmasıyla sürdürülen kontroller dış mekanda kullanılacak pano yerlerinin ve pano mesajlarının son halinin şekillenmesini sağlamıştır.

Pano mesajlarında öncelik acil durum noktaları (Acil Servis, Kan Merkezi vb.) ile temel geliş noktaları olan poliklinikler ve servislere verilmiş, bununla birlikte pano yakınlarında kullanıcıyı ilgilendiren birimler de sıralamada yerini almıştır. Böylece üç katman halinde kullanıcıların hastane alanlarını kullanabilmesi sağlanmaya çalışılmıştır. Birinci katman ana yoldan hastane alanına geçiş noktası olarak düşünülmüş, günlük hasta girişleri ile acil hasta girişleri bu noktada ayrıştırılmıştır. Ikinci katman hastane alanı içerisinde poliklinik ve servis birimlerin arasında verilen karar üzerine oluşturulmuş ve birbirinden farklı amaçlar için hastanede bulunan kullanıcılar birbirinden ayrıştırılmıştır. Üçüncü ve son katmanda ise iç mekanlarda her kullanıcının hedefine varması şeklinde çözümlenmiştir.

İç ve dış mekana ait farklılıklar ile kullanıcı profiline ait özel durumlar dikkate alınarak oluşturulan yönlendirme stratejisi, kullanıcıların hastane ile görsel iletişim bağı hiç kopmadan güvenle, hızla ve konforlu bir biçimde hedefe varmalarını sağlamayı amaçlamaktadır.

\section{Kaynakça}

Arthur, Paul ve Passini, Romedi (1992). Wayfinding: People, Signs and Architecture, New York: McGraw-Hill Book Company.

Calori, Chris (2007). Signage and Wayfinding Design, America: John Wiley and Sons.

Güler, Tuğcan (2008). Grafik Tasarımda Yeni Bir Alan: Bilgilendirme Tasarımı ve Bir Uygulama, Yayınlanmamış Sanatta Yeterlik Tezi, İzmir: Dokuz Eylül Üniversitesi Güzel Sanatlar Enstitüsü.

Lynch, Kevin (1960). The Image Of The City, Boston: The MIT Press. Lynch, Kevin (1996). “Kent ve Kent Kültürü”, Cogito Dergisi (8): Mollerup, Per (2005). Wayshowing A Guide to Environmental Signage Principles\&Practices, Zürih: Lars Müller Publishers.

Muhlhausen, John (2001). Signs of the Times Magazine, Australia: Signs of the Times

Uebele, Andreas (2007). Signage Systems \& Information Graphics, Londra: Thames\&Hudson

\section{İnternet Kaynakları}

Hogan, Dennis, (2004). "The Way-Finding in the Build Environment Project", www.construction-innovation.info

(TDK). http://www.tdk.gov.tr/index.php?option=com_ gts\&arama=gts\&guid=TDK.GTS.539193dd7fb8a9.97195239

\section{Görsel Kaynaklar}

Resim 1. Çin Mahallesi, Manhattan, New York, 2012. (Fotoğraf: Tuğcan GÜLER)

Resim 2. Antik Roma, İtalya, 2006. (Calori, 2007: 2).

Resim 3. Brigham and Woman Hastanesi, Boston ABD, 2005. (Fotoğraf: Tuğcan Güler)

Resim 4. Ortaçağ'dan Kalma Yönlendirme Çalışmaları, Bristol, İngiltere, 2007,

http://www.mediabyjohn.com/way_final/history.html (20.05.2014)

Resim 5. Avustralya Teknoloji Parkı, Sydney, 2011,

http://theblueprint.com.au/wp-content/ uploads $/ 2012 / 08 /$ Blueprint-ATP-07thumbnail.jpg (16.05.2014) 
Resim 6. Dokuz Eylül Üniversitesi Hastanesi Bahçesi, 2013. (Fotoğraf: Tuğcan Güler)

Resim 7. Cadde ve Sokaklar, Manhattan, New York, ABD, 2012. (Fotoğraf: Tuğcan Güler)

Resim 8. Kavşak Noktası, Queens, New York, ABD, 2012. (Fotoğraf: Tuğcan Güler)

Resim 9. Kontrolsüz Kavşak, İngiltere, 2010, Rural Road Intersection, Image by Howard Kingsnorth/Corbis (16.12.2010)

Resim 10. Krakow Havalimanı, Krakow, Polonya, 2013,

http://www.thinkingarchitects.com/wp-content/ uploads $/ 2013 / 09 / \mathrm{krakow}$-airport-wayfinding-strefyinformacyjne-pietro-1810x1280.png (03.06.2014)

Resim 11. Dokuz Eylül Üniversitesi Hastanesi, İzmir, 2013. (Fotoğraf: Tuğcan Güler)

Resim 12. Hastanede Dış Mekan Kavşak Noktaları, Proje Dosyasından alınmıştır, 2013. (Fotoğraf: Tuğcan Güler)

Resim 13. Hastane iç mekanda yerleşim, Proje Dosyasından alınmıştır, 2013. (Fotoğraf: Tuğcan Güler)

Resim 14. JFK Havalimanı, New York, ABD, 2006. (Mollerup, 2005: 248).

Resim 15. Ham Totemler, Proje Dosyasından alınmıştır, 2013. (Fotoğraf: Tuğcan Güler)

Resim 16. Mass General Hastanesinden Proje Görselleri, Boston, ABD, 2005. (Fotoğraf: Tuğcan Güler)

Resim 17. Örnek Totem Tasarımı, Proje Dosyasından alınmıştır, 2013. (Fotoğraf: Tuğcan Güler)

Resim 18. Stratejik Planlama Maketi, Proje Dosyasından alınmıştır, 2013. (Fotoğraf: Tuğcan Güler) 